\title{
Ascertaining Problems with Medication Histories
}

\author{
Henry Halapy and Heather Kertland
}

\begin{abstract}
Background: Accurate and complete medication histories are not always obtained in clinical practice.

Objective: This qualitative research study was undertaken to explore the barriers to and facilitators of obtaining accurate medication histories.
\end{abstract}

Methods: Individual interviews, based on a structured interview guide, were conducted with 25 patients from both inpatient and ambulatory care clinic settings. Focus groups, based on a semistructured interview guide, were conducted with pharmacists, medical residents, and nurses. Transcribed data were analyzed by forming coded units and assessing these units for emerging themes.

Results: Major themes that emerged from the patient interviews included patient ownership of health and medication knowledge (with knowledge of medications and their side effects and how to take medications being seen as important), patient-specific strategies to improve medication histories (e.g., use of regularly updated medication lists), and suggestions for system-level facilitators to improve medication histories (e.g., centralized databases of medication histories, increased patient education regarding the use and purpose of medications). Major themes also emerged from focus groups with health care professionals, including shared responsibility for medication history-taking among all 3 health care professions, perceptions about the barriers to medication history-taking (including patients not knowing their medications and not bringing their medication lists), and suggestions to improve medication histories (e.g., educating patients to bring medication vials to hospital admissions and appointments, using a centralized computer database for medication histories).

Conclusions: Key recommendations resulting from this study include using standardized documentation techniques for medication histories, recording of medication history information in centralized electronic databases, educating patients to bring medications to every health care visit, and establishing criteria for pharmacist referral for cases involving complex medication histories.

Key words: medication history, focus group, barriers and facilitators

Can J Hosp Pharm 2012;65(5):360-367

\section{RÉSUMÉ}

Contexte : Les histoires médicamenteuses précises et complètes ne sont pas toujours obtenues en pratique clinique.

Objectif : La présente recherche qualitative a été menée pour examiner les obstacles et les aides à l'obtention d'histoires médicamenteuses précises.

Méthodes : Des entrevues individuelles structurées ont été effectuées avec 25 patients hospitalisés ou traités dans une clinique de soins ambulatoires. Des groupes de discussion, à l'aide d'un guide d'entrevue semi-structurée, ont été menés avec des pharmaciens, des médecins résidents et du personnel infirmier. Les données transcrites ont été analysées en développant des unités codées et en évaluant ces dernières à la recherche de thèmes émergents.

Résultats : Les principaux thèmes ayant émergé des entrevues avec les patients étaient notamment leur responsabilité à l'égard de leur santé et leur connaissance des médicaments (la connaissance des médicaments, de leurs effets secondaires et de la façon de les prendre étant vue comme importante), les stratégies propres au patient pour améliorer les histoires médicamenteuses (p. ex., le recours à des listes de médicaments mises à jour périodiquement) et les suggestions d'aides au niveau des systèmes permettant d'améliorer les histoires médicamenteuses (p. ex., bases de données centralisées sur les histoires médicamenteuses, information accrue des patients sur l'utilisation et le but des médicaments). Des thèmes majeurs ont également émergé des groupes de discussion avec les professionnels de la santé, dont la responsabilité commune de la collecte des histoires médicamenteuses par les trois professions représentées, les perceptions des obstacles à cette collecte (notamment les patients qui ne connaissent pas les médicaments qu'ils prennent et ceux qui n’apportent pas leurs listes de médicaments) et les suggestions d'aides à l'amélioration des histoires médicamenteuses (p. ex., sensibiliser les patients sur l'importance d'apporter leurs flacons de médicaments lors d'admission ou de rendez-vous à l'hôpital, l'utilisation d'une base de données informatique centralisée sur les histoires médicamenteuses).

Conclusions : Les principales recommandations issues de cette étude sont notamment de recourir à des techniques de constatation des histoires médicamenteuses standardisées, de consigner les renseignements sur les histoires médicamenteuses dans des bases de données informatiques centralisées, de sensibiliser les patients à l'importance d'apporter leurs médicaments à chaque consultation d'un professionnel de la santé et d'établir des critères pour les demandes de consultation aux pharmaciens pour les cas comportant des histoires médicamenteuses complexes.

Mots clés : histoire médicamenteuse, groupe de discussion, obstacles et aides

[Traduction par l'éditeur] 


\section{INTRODUCTION}

$\mathrm{M}$

edications play an important role in the care of patients within the organized health care setting. When a patient presents to hospital, it is important that prior medications be assessed to determine if they need to be continued, temporarily held, or permanently discontinued during that hospital stay. This process, now called medication reconciliation, is a required organizational practice within Accreditation Canada standards. ${ }^{1}$ Medication reconciliation requires that a best possible medication history be obtained upon admission. Despite the need for an accurate medication history, such a history is often not obtained. In a systematic review, Tam and others ${ }^{2}$ found that the frequency of at least one error in the medication history ranged from $27 \%$ to $83 \%$ and from $10 \%$ to $67 \%$ if only prescription medications were considered. The number of medication errors ranged from 0.3 to 2.7 per patient. Furthermore, these errors in medication histories can have clinical consequences. Cornish and others ${ }^{3}$ determined that $53.6 \%$ of the patients in their study had at least one medication error, and $38.6 \%$ of the discrepancies had the potential to cause moderate or serious harm to patients.

Although it is recognized that complete and accurate medication histories are not always obtained in clinical practice, information is lacking as to why this problem occurs and the potential solutions. Studies that have examined medication errors have listed, in a post hoc manner, possible barriers to obtaining a history, including time required to obtain a history and inadequate training in the skill of obtaining medication histories, as well as the patient's illness and knowledge of his or her medications. ${ }^{4-7}$. What is not available is a prospective exploration among those involved in providing and obtaining medication histories of their insights into the process. The purpose of this study was to explore perceived barriers to and facilitators of obtaining medication histories, with the goal of identifying themes and potential recommendations to improve the process.

\section{METHODS}

This qualitative research study took place at St. Michael's Hospital, an academic tertiary care hospital in Canada. The study was approved by the St. Michael's Hospital Research Ethics Board. All patients were asked to provide written, informed consent. Informed consent was assumed to have been given by health care professionals who participated in the focus groups.

\section{Patients Sample}

Twenty-five patients were recruited from a variety of medical and surgical floors, as well as ambulatory care clinics.
Patients who did not speak English and those unwilling to give informed consent were excluded from the study. Patients were recruited through direct advertisement during routine clinical appointments or hospital stays or by soliciting health care professionals who were taking care of the patients.

\section{Interviews}

Individualized patient interviews were administered by a trained interviewer using a structured interview guide (see Appendix 1, available at www.cjhp-online.ca/index.php/ cjhp/issue/view/89/showToc). Neither the interviewer (a female health care professional with a pharmacy background) nor the researchers were involved in the care of these patients. Key areas of questioning included the importance of medication histories to the patient, problems with not knowing all of one's medications, barriers to obtaining accurate medication histories, and potential solutions to the problems with the medication historytaking process. The interview guide was tested with 2 key informants for face and content validity and appropriateness of the questions before use with patients. All interviews were audiotaped, and handwritten notes were taken during each interview. There were no repeat interviews, nor were transcripts returned to interviewees for review.

\section{Health Care Professionals Sample}

Pharmacists, medical residents, and nurses were recruited from a variety of patient care settings. Pharmacists and nurses were primarily recruited by announcements at staff meetings, posters, and e-mail messages. Medical residents were recruited by e-mailing the advertising poster for the study to the chief medical resident and department heads for distribution.

\section{Focus Groups}

Focus groups were conducted within each health care professional group to maximize contributions and minimize hierarchical influence. ${ }^{8}$ Three focus groups were conducted for each health care professional group, to allow for sufficient data collection and saturation. A semistructured pilot interview guide was created, which included the importance of accurate medication histories, responsibilities related to the medication history-taking process, and problems with and solutions for this process (see Appendix 2, available at www.cjhp-online.ca/ index.php/cjhp/issue/view/89/showToc). The interview guide was tested with 2 key informants for face and content validity and appropriateness of the questions before implementation with the larger focus groups.

A trained facilitator (a female research assistant who did not have a health care background) led each focus group session. One of the researchers (H.H.) also attended each focus 
group to take field notes and to audiotape each session. At the end of each focus group, participants were given a sheet for additional comments. Each participant was asked to provide demographic data, specifically years of training, years of work experience, age, and sex.

\section{Data Analysis and Interpretation}

Demographic data were summarized with descriptive statistics. Audiotapes were transcribed to create unabridged transcripts, and the researcher's field notes were appended to each transcript. The unabridged transcripts were analyzed in their entirety, and then the complete set of narrative experiences of patients and health care professionals was broken down into significant statements by manually forming coded units. ${ }^{8}$ This process was conducted independently by the 2 researchers (H.H. and H.K.). The coded units were then grouped into themes. The themes were identified and formulated through reflection consistent with a grounded theory approach and consensus agreement by the 2 researchers. Recommendations were formulated from the themes and the related data. Participants' feedback regarding the themes was not solicited after the coding process.

\section{RESULTS Patients}

Twenty-five patients (12 women and 13 men) were recruited for interviews, coming from both inpatient (surgical and medical) units and ambulatory clinics. Patients ranged in age from 30 to 80 years (mean 65 years). Patients' responses were organized into 4 themes (Table 1).

Theme 1: Ownership of Health and Medication Knowledge

Patients felt that knowledge of their medications was important because they needed to know which medications to take, how and when to take them, and the correct doses. Understanding and identifying benefits, adverse effects, and purposes of medications were also felt to be important. Patients also wished to use nonprescription medications safely. Ultimately, patients desired to be active participants in, and wished to take personal responsibility for, their own health and medications. If patients were to function as active participants in their health care and were consistently aware of their medications and changes to their medications, accurate medication histories could potentially be easier to obtain and more reliable.

\section{Table 1. Relevant Quotations Organized by Themes: Patients}

\section{Theme}

1: Ownership of health and medication knowledge

2: Identified consequences of incomplete
or inaccurate information

Sample Quotations

"If I don't know what I'm taking and what's changing, how I can expect to keep on top
of my own personal health?"

"Yes, I have to be an active participant in my own health care."

" ... if you're going to any kind of a health care professional, you're going for a

reason and they need to know accurate information to be able to treat you."

"... critical information to the care that's being provided to me."

"... what they [medications] are is that you might actually do things which diminish their effectiveness or conflict with their effects or perhaps precipitate symptoms or side effects that are associated with them. And similarly, if health care professionals don't know, then ... they may prescribe medication or other therapies which are contrary to or in conflict with your existing medication."

3: Patient-specific strategies to improve "... when they [health care professionals] can see first-hand what [medication] it is, [it] medication histories

saves time and increases accuracy."

"I know them by memory, ... If it's kind of drastic change, or if I have a lot going on, I tend to write it down."

"Also, education is very important. It reinforces your confidence."

"The patient themselves knowing what's happening and you know ... understanding what the medication is about ..."

4: Suggestions for system-level facilitators to improve accuracy of medication histories
"... a single network where your meds are listed ..." or "... set up a database so that all medications ... be captured under an OHIP number ..." or "sort of electronic records, smart card ... or some other in hospital records ..."

"... I think that there should be some generic branding in the labeling system, ..., Lipitor [atorvastatin] is the same as every other cholesterol-reducing medication, but they should be known as a group of medications. If you go to the supermarket and you want to get dishwasher detergent, it doesn't have to be called Sunlight or Tide or anything, the person that you ask will immediately know what you're asking about and they'll point you in the right direction. There isn't that same convenience or ease of use with medications, that simple communication, ... if you don't know the name of the medication, it's a block or a hurdle to being able to communicate clearly about it." 
Theme 2: Identified Consequences of Incomplete or Inaccurate Information

Patients unanimously agreed that pharmacists, physicians, and nurses should have complete medication histories. They agreed that it is important to accurately communicate medication information to health care professionals so that they (the patients) can receive maximal benefit from health care visits. Patients acknowledged that accurate medication histories are essential to assess future changes in medication therapy, to assess the effectiveness of medications, and to avoid medication interactions.

Patients expressed no reluctance to share information about their medications with health care professionals. Not remembering their medications and not bringing their medication vials to health care visits were felt to be critical issues that could affect the care being provided.

Theme 3: Patient-Specific Strategies to Improve Medication Histories

Patients described the need to be able to readily list their medications. The most commonly cited methods included bringing a list of medications (either handwritten or computergenerated) or medication vials to appointments. Patients cited reliance on family members, medical records, and their own memories less commonly. Supplemental methods cited in providing accurate medication data included keeping regular appointments with health care providers, placing a phone call to update physicians and other health care practitioners about changes to medications, and using only one pharmacy for dispensing of medications. These supplemental methods were seen as potentially important contributors to accurate medication histories, as they help to ensure that all health care professionals have up-to-date medication lists, thus improving the whole medication history-taking process. Overall, taking more responsibility for their medications was also cited as important. However, to ensure the accuracy of medicationrelated information, patients noted that they required ongoing education from health care professionals about any changes made to their medications.
Theme 4: Suggestions for System-Level Facilitators to Improve Accuracy of Medication Histories

Patients had several system-level recommendations, including reinforcement of the importance of medication knowledge, use of computerized records as a documentation system, and simplification of medication names.

Some form of a central computerized solution was suggested frequently, such as a single network listing medications captured through the patient's OHIP number, a smart card for electronic records, or some other mode of recording medications in patients' hospital records.

Development of easier-to-remember names and spelling of medications, including use of more intuitive medication names, was cited as a strategy to improve patients' ability to provide accurate medication histories.

\section{Health Care Professionals}

Three focus groups were conducted for each of the health care professions: pharmacists, medical residents, and nurses. These health care professionals worked in both inpatient and outpatient settings. In total, 12 pharmacists, 6 physicians, and 15 nurses participated in the focus groups (see Table 2 for demographic characteristics). Responses from health care professionals were organized into 5 themes (Table 3).

Theme 1: Components and Benefits of an Accurate Medication History

Representatives of all professions agreed that accurate medication histories were important and should consist of names of medications (both prescription and nonprescription), indications, directions for use, and duration of therapy. Allergies, adverse effects of medications, availability of medication insurance, and contact information for the patient's community pharmacy and family physician were also considered to be part of the medication history. All of this information was felt to be important in providing continuity of care to patients.

Other benefits of medication histories noted in the focus groups included the identification of medication-related diagnoses. Medication histories can also be used to help

Table 2. Demographic Characteristics of Health Care Professionals in a Study of Medication History-Taking

\begin{tabular}{lcccc}
$\begin{array}{l}\text { Profession* (No. in } \\
\text { Each Focus Group) }\end{array}$ & $\begin{array}{c}\text { Mean Years } \\
\text { of Experience }\end{array}$ & $\begin{array}{c}\text { Mean Years in } \\
\text { Current Position }\end{array}$ & $\begin{array}{c}\text { Mean Age } \\
\text { (years) }\end{array}$ & $\begin{array}{c}\text { Sex Ratio } \\
\text { (Female:Male) }\end{array}$ \\
\hline $\begin{array}{l}\text { Pharmacists } \\
(n=5,4,3)\end{array}$ & 6.8 & 4.3 & 30.9 & $11: 1$ \\
\hline $\begin{array}{l}\text { Physicians } \\
(n=2,1,3)\end{array}$ & 7.3 & 1.4 & 33.5 & $3: 3$ \\
\hline $\begin{array}{l}\text { Nurses } \\
(n=4,3,8)\end{array}$ & 12.8 & 4.3 & 40.4 & $15: 0$ \\
\hline
\end{tabular}


This single copy is for your personal, non-commercial use only.

For permission to reprint multiple copies or to order presentation-ready copies for distribution, contact CJHP at cjhpedit@cshp.ca

\section{Table 3. Relevant Quotations Organized by Themes: Health Care Professionals}

Theme

1: Components and benefits of an accurate medication history

\section{Sample Quotations}

"It can participate a lot in patient care, ..., it can participate even in the diagnosis of the disease of the patient."

"I think the history's not only what they're prescribed or not what they're taking, but a combination of both, what they're prescribed and how they're actually taking it ...."

"I find the patient interview, actually having the vials in front of me, going through them one by one, this is what you take, how many pills, regardless of what it says on the bottle, what does the patient tell me, ..., then I guess second would be any printout from any pharmacies, what medications do they provide, third would be I guess a note from other physicians saying what they've prescribed."

2: Shared responsibility for medication history-taking among all 3 health care professions

"I think in my opinion it is the one, the doctor who treats the patient, he must take the medication history, it's a must. ... doctors who admit the patient, we have to be really sure of what medicines the patients are taking, and definitely what they were prescribed, and which doses they were prescribed, ...." [physician]

"... I agree the two disciplines that should have the most ownership should be the physicians, because they are the ones to be prescribing the medication once the patient comes into hospital, but I think it's also the pharmacist's role, because we are the drug experts, so we need to collect an accurate medication history in order to prevent drug-related problems or to intervene properly ... I think the responsibility should also be with nursing as well, because there's a nurse who cares for the patient ...." [pharmacist]

"I think it's shared yes, ... the doctor's responsibility is more so, probably $70 \%$, because they're the ones prescribing medications, we can't do it. We often find the mistakes ...." [nurse]

3: Perceptions about medication history documentation

"... in terms of our documentation any computer-based solution stands to be an improvement, because I think fewer transcription errors would occur, and there would be more clarity, there would be better communication with the nurses, we wouldn't have to decipher bad handwriting, or inappropriate doses, and built into computer systems are intelligent design systems that can anticipate what you're writing ...."

4: Perceptions about barriers to " "... in elderly patients [who are taking] a lot of medications and especially in the middle medication history-taking of the night, they don't have their medications with them, it's really hard to know what medications, and because you need to write the admission orders for them, and they don't have their medications, they don't know the medications that they're taking, and then if the pharmacy's not 24 hours there's no way to track down what medications they take, ... so they miss dosing, doses because of that."

"... I think the other problem is lack of communication between the family doctor, the surgeon, the specialist, ... so they'll make changes and the family doctor's not aware, and then I have to contact the family MD and all the specialists to get a complete history, ...."

5: Suggestions for system-level facilitators to improve accuracy of medication histories "Access to records ... and a lot of our admissions come in after hours, so if there were ways to liaise easily with community pharmacists, that would be a facilitator."

"If the patient comes in armed with knowledge, or some knowledge, that goes a long way."

"... they should put an ad in the newspaper and say if patient's coming to hospital, please bring your pill bottles with you."

ascertain the patient's adherence with the medication regimen, by comparing the patient's description of how he or she is taking the medications with the prescribed mode of taking the medications.

Health care professionals felt that patients' own lists or pharmacy medication vials should be used as a baseline for medication histories. Other sources of baseline medication history information identified during the focus groups included the community pharmacy, the family or caregivers, family physicians, medication administration records from nursing homes, and prescription vials or blisters. However, the health care professionals felt that it would be important to talk to the patient to confirm the accuracy of the medication list and thus to obtain a single accurate medication list. One pharmacist described a hierarchy in the approach to obtaining an accurate medication history: first, going through the patient's vials, to see first-hand what he or she has been taking, then using a printout from the patient's community pharmacies to find out what has been dispensed, and finally, using physician notes to determine what has been prescribed. 
Theme 2: Shared Responsibility for Medication HistoryTaking Among All 3 Health Care Professions

Health care professionals felt that taking a medication history was a responsibility to be shared among all 3 health care professions. The pharmacists, physicians, and nurses felt that physicians had primary responsibility for determining medication histories, with pharmacists being needed to clarify discrepancies and other complex issues. Nurses felt that they had a role in clarifying discrepancies in the medication history, especially if no pharmacist was available.

Theme 3: Perceptions about Medication History Documentation

Health care professionals agreed that standardized, electronic, multidisciplinary forms were needed for efficient documentation of medication histories. Such forms would also allow easy retrieval of the information. The barriers to documentation reported by focus group participants included time, physical space, computer access, duplication of work (because multiple places to document medications exist in a patient's chart), and other professionals not reading the documentation. The identified facilitators to improved documentation of the medication history were increased computer or terminal access, use of personal digital assistants (PDAs) to input information related to the medication history, use of preprinted forms, and placement of the medication history on the front of the chart, where it can be easily seen.

Theme 4: Perceptions about Barriers to Medication HistoryTaking

All 3 groups of health care professionals identified patients' lack of knowledge about their medications, patients' mental state and language, and the inability to contact patients' care providers as barriers to medication history-taking. Pharmacists identified patients putting all pills in one vial and lack of communication between physicians and pharmacists as additional barriers. Coordinating medication history information among a patient's various specialists was a time-consuming procedure for pharmacists.

Physicians noted that useful sources of information, such as pharmacies or physicians' offices, were not available at night. Deficiencies of the Ontario Drug Benefit (ODB) database (e.g., lack of complete histories, insufficient details about exact doses) were cited as an additional barrier.

Theme 5: Suggestions for System-Level Facilitators to Improve Accuracy of Medication Histories

Medical residents suggested several facilitators to obtaining medication histories: storing a list of medications on a centralized computer system; having an easier way to liaise with community pharmacies regarding medication histories; educating patients to bring their medication vials to appointments; educating patients to use one pharmacy for all of their prescriptions; using pictures, PDA software, or smart phone software to help in identifying medications; asking patients to carry small medication charts in their wallets; and having more detailed medication information in the ODB system. The ability to access the medication records of community pharmacies after hours was seen as a particularly important facilitator.

Pharmacists also saw the benefits of using sample tablets or photos of medications, developing a standardized documentation system, improving access to community pharmacy resources, and increasing the time available to obtain medication histories, including the commitment of emergency room resources to this task. Ultimately, patients' knowledge of their medications, or at least ensuring that patients bring their medication vials or medication lists, seemed very important to pharmacists.

Nurses had similar recommendations, including better links with patients' community pharmacies, use of one pharmacy to fill prescriptions, a centralized computer system of medications, use of pictures to help identify medications, patients' use of a diary for medications and other health information, and education of patients to bring their medication vials to admissions and appointments (e.g., placing public service advertisements in newspapers asking patients to take their medications when they go to hospital and explaining why).

\section{Recommendations}

Five key recommendations were derived from the data summarized above. (1) The use of standardized documentation techniques for medication histories (either in electronic format or preprinted forms) was a key point shared by all health care professionals and patients. (2) Both patients and health care professionals agreed that recording medication history information in electronic databases, to facilitate appropriate sharing of information among health care providers, was important. Electronic availability of information would help with accessing medication lists after hours and would help to address patients' concerns about inaccuracy or incompleteness of medication history records. (3) Educating patients about their medications, specifically the need to bring medications to every hospital visit, was an important viewpoint of all health care professionals. (4) Although health care professionals recognized the importance of sharing the responsibility for medication history-taking among all 3 professions, pharmacists felt that their skills would be best used for specialized cases. This points to the importance of criteria for referral to a pharmacist in cases of complex or discrepant medication histories. (5) All 3 groups of health care professionals felt that techniques and tools such as medication pictures were an important aid in obtaining medication histories.

\section{DISCUSSION}

Interviews with patients and focus groups involving health care professionals were conducted to elicit facilitators and 
barriers related to the medication history-taking process. Several important themes emerged from both groups of participants, including the importance of medication histories, problems with documentation of medication histories, barriers to obtaining medication histories, and facilitators and solutions to medication history problems at the patient, caregiver, and system levels. To date, problems with the medication reconciliation process have largely been addressed at the system level, rather than the level of patient or caregiver, through varied interventions to make the process of obtaining a medication history more efficient and more effective. ${ }^{4-7,9-14}$

Both patients and health care professionals discussed the importance of medication histories and their role in safe and effective health care. This importance was related not only to the use of medication histories in prescribing additional medications, but also their use as an aid in determining past medical histories and diagnoses and in identifying and preventing drug therapy problems. This study revealed a "disconnect" between patients' knowledge of the importance of medication histories and health care professionals' experience that patients often could not provide the necessary information about their medications. Although the patients recognized the need for ongoing education about their medications and medication changes, not all health care professionals recognized patient education as a way to improve medication histories or provided concrete examples of how such education might be provided and/or whose responsibility it would be. Presumably, though, more knowledgeable patients would be in a better position to provide accurate medication histories.

The health care professionals did identify a need to educate patients about having a medication list with them. This would include instructing patients to bring their medication vials to health care visits. Such a practice could be implemented not only at the level of educating individual patients, but also at a hospital-wide or even province-wide level in the form of public service advertisements. It would also be important to educate patients about understanding the names of their medications and the purpose for taking them.

Health care providers saw that obtaining medication histories was a responsibility shared among all 3 groups, with physicians providing the initial medication histories and pharmacists and nurses providing a check on the histories. Despite recognition that all 3 professions had a role, the suggested approach was hierarchical, with physicians being ultimately responsible. The reasons for favouring this hierarchical approach were not probed further. The pharmacists thought that their role was critical in resolving issues related to more complex medication histories. This suggests the importance of having criteria for referral to pharmacists for specific complex medication history-taking. Nurses also suggested that they had a role in obtaining medication histories, especially if no pharmacist was present, but they did not outline why they should not be involved in performing this task for a greater number of patients than is currently the case.

Problems with access to and documentation of medication histories were described by all of the health care professional groups and by patients. Use of a centralized database for storing patients' medication lists was seen as very important in obtaining accurate medication histories, especially by physicians. The recommendation to leverage technology would include not only having electronic information available for all patients (rather than just those over 65 years of age, as is currently the case) but also having a wider range of information available, such as dosing details. The use of online prescription records to reconcile medication information obtained during structured interviews has been attempted in other jurisdictions, where it was found to reduce recall bias. ${ }^{15}$ There was also agreement that documentation of the medication history should appear in only one physical or virtual location in the medical chart and that all personnel should have access to it. In a randomized trial in a preadmission surgical setting, Kwan and others $^{16}$ assessed use of a standardized documentation format coupled with pharmacist interviews, relative to standard practice. They found that this approach significantly reduced postoperative medication discrepancies and omission of home medications.

Aids to show the appearance of medications (e.g., posters, sample tablets, pictures on electronic devices) were suggested as important tools in identifying medications. Such aids would be inexpensive, simple to construct, and easy to implement. They have been used in the clinical setting with some success, increasing patients' recall of medications by $6 \%$ over unassisted recall in one study. ${ }^{17}$ Lesselroth and others ${ }^{18}$ combined medication pictures with technology, automating the process of medication history-taking through the use of consumer-based kiosks and comparing the information obtained with existing health records and interviews. Use of medication pictures and kiosks allowed detection of at least one discrepancy for $90 \%$ of all care encounters.

Having a mix of health care professionals in the focus groups might have elicited additional information through cross-fertilization of ideas among the groups. However, the decision to keep the groups separate was deliberate, to minimize hierarchical influences. ${ }^{8}$ Another limitation of this study was that one physician focus group was attended by a single physician. Although the opinions expressed by this person were consistent with those expressed by the other physician groups, the interactions inherent to a focus group were missing.

\section{CONCLUSIONS}

Medication reconciliation is recognized as a major patient care initiative and an accreditation standard. It is therefore 
important to explore perceived barriers and facilitators to obtaining medication histories and to identify recommendations to improve the accuracy of medication history-taking. ${ }^{1}$ The 5 key recommendations resulting from this study were to use standardized documentation techniques for medication histories, to record medication history information in electronic databases (to allow appropriate sharing), to educate patients to bring their medications to every hospital visit, to establish criteria for pharmacist referral for specific types of medication histories, and to use techniques and tools such as pictures to help with medication histories. Additional research is needed to enhance understanding of the medication reconciliation process, particularly in terms of determining the most appropriate use of documentation techniques and electronic databases.

\section{References}

1. Required organizational practices 2012. Ottawa (ON): Accreditation Canada; 2012 [cited 2012 Sep 17]. Available from: www.accreditation.cal uploadedFiles/ROP\%20Handbook.pdf

2. Tam VC, Knowles SR, Cornish PL, Fine N, Marchesano R, Etchells EE. Frequency, type and clinical importance of medication history errors at admission to hospital: a systematic review. CMAJ 2005;173(5):510-515.

3. Cornish PL, Knowles SR, Marchesano R, Tam V, Shadowitz S, Juurlink $\mathrm{DN}$, et al. Unintended medication discrepancies at the time of hospital admission. Arch Intern Med 2005;165(4):424-429.

4. Nester TM, Hale LS. Effectiveness of a pharmacist-acquired medication history in promoting patient safety. Am J Health Syst Pharm 2002; 59(22):2221-2225.

5. Dutton K, Hedger N, Wills S, Brown D, Davies P. Prevent medication errors on admission. Clin Gov Int J 2003;8(2):128-137.

6. Michels RD, Meisel SB. Program using pharmacy technicians to obtain medication histories. Am J Health Syst Pharm 2003;60(19):1982-1986.

7. Lau HS, Florax C, Porsius AJ, De Boer A. The completeness of medication histories in hospital medical records of patients admitted to general internal medicine wards. Br J Clin Pharmacol 2000;49(6):597-603.

8. Krueger RA, Casey MA. Focus groups: a practical guide for applied research. 3rd ed. Thousand Oaks (CA): Sage Publications, Inc; 2000.

9. Mersfelder TL, Bickel RJ. Inpatient medication history verification by pharmacy students. Am J Health Syst Pharm 2008;65(23):2273-2275.
10. Pippins JR, Gandhi TK, Hamann C, Ndumele CD, Labonville S, Diedrichsen EK, et al. Classifying and predicting errors of inpatient medication reconciliation. J Gen Intern Med 2008;23(9):1414-1422.

11. Slain D, Kincaid SE, Dunsworth S. Discrepancies between home medications listed at hospital admission and reported medical conditions. Am J Geriatr Pharmacother 2008;6(3):161-166.

12. Andersen SE, Pedersen AB, Bach KF. Medication history on internal medicine wards: assessment of extra information collected from second drug interviews and GP lists. Pharmacoepidemiol Drug Saf 2003; 12(6):491-498.

13. Tattersall C, Hartry N, Ram ARR. Improving the accuracy of medication history taking in a diabetic eye clinic. Br J Nurs 2008;17(9):598-600.

14. Reeder TA, Mutnick A. Pharmacist- versus physician-obtained medication histories. Am J Health Syst Pharm 2008;65(9):857-860.

15. Glintborg B, Poulsen HE, Dalhoff KP. The use of nationwide on-line prescription records improves the drug history in hospitalized patients. $\mathrm{Br}$ J Clin Pharmacol 2007;65(2):265-269.

16. Kwan Y, Fernandes OA, Nagge JJ, Wong GG, Huh JH, Hurn DA, et al. Pharmacist medication assessments in a surgical preadmission clinic. Arch Intern Med 2007;167(10):1034-1040.

17. Kimmel SE, Lewis JD, Jaskowiak J, Kishel L, Hennessy S. Enhancement of medication recall using medication pictures and lists in telephone interviews. Pharmacoepidemiol Drug Saf 2003;12(1):1-8.

18. Lesselroth B, Adams S, Felder R, Dorr DA, Cauthers P, Church V, et al. Using consumer-based kiosk technology to improve and standardize medication reconciliation in a specialty care setting. Jt Comm J Qual Patient Saf 2009;35(5):264-271.

Henry Halapy, PharmD, is with St Michael's Hospital, Toronto, Ontario.

Heather Kertland, BScPhm, PharmD, is with St Michael's Hospital and the Leslie Dan Faculty of Pharmacy, University of Toronto, Toronto, Ontario.

\section{Address correspondence to:}

Henry Halapy

Pharmacy Department

St Michael's Hospital

30 Bond Street

Toronto ON M5C 2T2

e-mail: halapyh@smh.ca

\section{ON THE FRONT COVER}

\section{View from Mount Temple, Alberta}

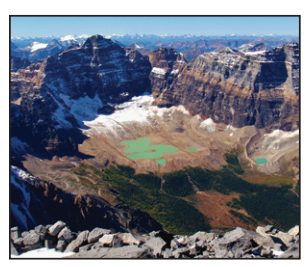

This photograph was taken on September 4, 2010, from the top of Mount Temple. At $3544 \mathrm{~m}$, Mount Temple is the second-highest peak in Banff National Park and the seventhhighest in the province of Alberta. It is located in the Lake Louise mountain group, adjacent to Moraine Lake, and can easily be seen from the Trans-Canada Highway. This photo was taken looking southwest over Paradise Valley, with Lake Opabin in the centre, Mount Hungabee top centre, and Mount Lefroy on the right.
For this shot, Patrick Jones (a third-year student in the Faculty of Pharmacy and Pharmaceutical Sciences at University of Alberta) used an Olympus Tough point-and-shoot camera. From the summit, Patrick and his climbing companions quickly descended the scree slopes to enjoy a chilled celebratory beer in the Moraine Lake parking lot.

The CJHP would be pleased to consider photographs featuring Canadian scenery taken by CSHP members for use on the front cover of the journal. If you would like to submit a photograph, please send an electronic copy (minimum resolution $300 \mathrm{dpi}$ ) to Colleen Drake at cdrake@cshp.ca. 